\title{
PENENTUAN HARGA KONTRAK OPSI KOMODITAS EMAS MENGGUNAKAN METODE POHON BINOMIAL
}

\author{
I Gede Rendiawan Adi Bratha $^{1 \S}$, Komang Dharmawan ${ }^{2}$, Ni Luh Putu Suciptawati ${ }^{3}$ \\ ${ }^{1}$ Jurusan Matematika, Fakultas MIPA - UniversitasUdayana [Email: gederendiawan.1993@ gmail.com] \\ ${ }^{2}$ Jurusan Matematika, Fakultas MIPA - Universitas Udayana [Email: dharmawan.komang@gmail.com] \\ ${ }^{3}$ Jurusan Matematika, Fakultas MIPA - Universitas Udayana [Email: putusuciptawati@yahoo.co.id] \\ ${ }^{\S}$ Corresponding Author
}

\begin{abstract}
Holding option contracts are considered as a new way to invest. In pricing the option contracts, an investor can apply the binomial tree method. The aim of this paper is to present how the European option contracts are calculated using binomial tree method with some different choices of strike prices. Then, the results are compared with the Black-Scholes method. The results obtained show the prices of call options contracts of European type calculated by the binomial tree method tends to be cheaper compared with the price of that calculated by the Black-Scholes method. In contrast to the put option prices, the prices calculated by the binomial tree method are slightly more expensive.
\end{abstract}

Keywords: European Option, Binomial Tree method, Black-Scholes, gold commodity.

\section{PENDAHULUAN}

Derivatif merupakan sebuah kontrak perjanjian penukaran pembayaran yang nilainya diturunkan dari aset yang menjadi acuan pokok. Salah satu metode untuk menentukan nilai kontrak sebuah instrumen derivatif adalah metode pohon binomial (Binomial Tree). Metode ini berdasarkan pada percabangan pohon yang menerapkan aturan binomial pada tiap titik-titik percabangannya. Metode pohon binomial diadopsi untuk mempresentasikan pergerakan harga kontrak opsi suatu komoditas yang mengalami dua kemungkinan setiap periodenya, kemungkinan naik atau kemungkinan turun.

Menurut Tandelilin (2001), kontrak opsi merupakan suatu kontrak atau perjanjian antara dua pihak, dengan pihak pertama adalah sebagai pembeli yang memiliki hak untuk membeli atau menjual dari pihak kedua yaitu penjual terhadap suatu aset tertentu pada harga dan waktu yang telah ditentukan. Aktiva yang dibeli atau dijual dapat berupa saham, obligasi, mata uang, komoditas dan lainnya.
Kontrak opsi digunakan dengan harapan dapat mencegah risiko dan memaksimalkan keuntungan. Dalam mencegah risiko terhadap pergerakan harga pasar, diperlukan strategi yang tepat salah satunya dengan melakukan tindakan lindung nilai. Lindung nilai (hedging) dapat diterapkan baik pada instrumen keuangan dengan menggunakan kontrak opsi indeks seperti saham maupun dengan menggunakan kontrak opsi indeks komoditas seperti emas, minyak, kopi, gula dan lain-lain.

Komoditas merupakan suatu bahan baku atau benda nyata yang dapat diserahkan secara fisik, dapat disimpan untuk suatu jangka waktu tertentu dan dapat digolongkan menurut mutunya, yang biasanya mudah untuk diperjualbelikan. Dalam pasar global, perdagangan komoditas memainkan peran yang cukup penting, karena pada perdagangan komoditas, bursa komoditas mempertemukan pembeli dan penjual untuk memperdagangkan kontrak opsi atas komoditasnya. Masalah sering timbul ketika bahan baku komoditas yang diperlukan tidak terpenuhi dengan baik. Oleh 
karena itu, salah satu alternatif penyelesaiannya adalah melakukan perdagangan dengan kontrak opsi (option contract).

Metode lain untuk menentukan harga kontrak opsi selain metode pohon binomial salah satu di antaranya adalah metode Black-Scholes. Penentuan kontrak opsi suatu komoditas dengan metode Black-Scholes menggunakan parameterparameter awal seperti harga awal komoditas, tingkat suku bunga bebas risiko, volatilitas, dan periode (umur) kontrak opsi. Komoditas emas merupakan salah satu komoditas yang istimewa. Dalam kondisi mata uang yang fluktuatif nilai emas dapat bertahan tinggi, sehingga menjadikan emas sebagai alat penyimpan kekayaan yang baik.

Tujuan dari penelitian ini yaitu: (1) mengetahui hasil penentuan harga kontrak opsi suatu komoditas yang dihitung menggunakan metode pohon binomial; (2) mengetahui hasil perbandingan harga kontrak opsi yang dihitung menggunakan metode pohon binomial harga kontrak opsi suatu komoditas yang dihitung menggunakan metode Black-Scholes.

Tandelilin (2001) menyebutkan bahwa kontrak opsi merupakan suatu kontrak atau perjanjian antara dua pihak, dengan pihak pertama adalah sebagai pembeli yang memiliki hak untuk membeli atau menjual dari pihak kedua yaitu penjual terhadap suatu asset tertentu pada harga dan waktu yang telah ditentukan.

Pada dasarnya, metode Black-Scholes merupakan model yang banyak digunakan oleh masyarakat untuk menentukan opsi jual (put option) maupun opsi beli (call option). Model Black-Scholes dikembangkan pada tahun 1973 oleh Fischer Black dan Myron Scholes. Model ini hanya berlaku untuk penentuan harga opsi tipe Eropa (European option) dan tidak berlaku pada opsi tipe Amerika (American option).

Metode binomial pertama kali dikembangkan oleh Cox, Ross dan Rubenstein. Pohon binomial mensimulasikan suatu aset secara acak sebagai rangkaian gerakan naik atau gerakan turun. Gerakan naik atau turun ini sebanding dengan volatilitas aset. Nilai kontrak pada aset tersebut dievaluasi dan pada akhirnya nilai kontrak ini disebarkan kembali melalui cabang-cabang pohon (Mastro, 2013).

Nilai opsi jual tipe Eropa (European put option) saat $\mathrm{T}$ dapat dihitung dengan rumus:

$f_{i, j}=\max \left(K-S_{0} u^{j} d^{N-j}, 0\right)$.

Sedangkan nilai opsi beli tipe Eropa (European call option) saat $\mathrm{T}$ dapat dihitung dengan rumus:

$f_{i, j}=\max \left(S_{0}-K u^{j} d^{N-j}, 0\right)$

Selanjutnya, metode pohon binomial bergerak mundur dari $i=N-1 \mathrm{ke}=0$, sehingga harga opsi pada saat ke $i$ dihitung dengan rumus:

$f_{i, j}=e^{-r \Delta t}\left[p f_{i+1, j+1}+(1-p) f_{i+1, j}\right]$

\section{METODE PENELITIAN}

Langkah-langkah penentuan harga kontrak komoditas emas yaitu: (1) menentukan nilai return (Tingkat Pengembalian); (2) menghitung nilai statistika deskriptif dari data seperti mean, varian, skewness, dan kurtosis dari data harga komoditas emas; (3) estimasi nilai parameter awal yaitu $u, d$, dan $p$, kemudian dengan memasukan nilai parameter yang didapat ke dalam persamaan (1), (2) dan (3) akan didapatkan nilai kontrak opsi komoditas emas untuk setiap node pada pohon binomial; (4) menghitung harga kontrak opsi komoditas emas dari rata rata nilai komoditas yang telah didapat; (5) menghitung harga kontrak opsi komoditas emas menggunakan metode Black Scholes; (6) menginterpretasi nilai opsi dari kedua metode tersebut

\section{HASIL DAN PEMBAHASAN}

\section{Pemaparan Awal}

Data yang digunakan pada penelitian ini adalah data harga komoditas emas pada perusahaan Freeport-McMoRan Inc. (FCX) pada satu tahun terakhir periode 22 Juli 2015 sampai 22 Juli 2016 yang diperoleh dari alamat situs http://finance.yahoo.com. Pada data, yang digunakan adalah harga penutupan harian (close price). 


\section{Variabel-Variabel untuk Penentuan Harga Kontrak Opsi Tipe Eropa}

Dalam penentuan kontrak opsi tipe Eropa pada komoditas emas menggunakan metode pohon binomial terdapat variabel-variabel yang digunakan meliputi $S_{0}$ (harga komoditas awal), $T$ (waktu jatuh tempo), $K$ (Strike price), $r$ (suku bunga bebas risiko). Nilai $S_{0}$ dapat dilihat dari data historis harga kontrak opsi komoditas emas yang terakhir pada Freeport-McMoRan Inc. (FCX) periode 22 Juli 2015 sampai 22 Juli 2016 sebesar $\$ 12,87$. Nilai waktu jatuh tempo diperoleh dari lamanya kontrak pada kontrak opsi yaitu selama 3 bulan, sehingga nilai $\mathrm{T}$ sebesar 0,25. Harga pelaksanaan (strike price) disepakati antara penjual dan pembeli opsi yang dalam peneletian ini harga yang disepakati sebesar $\$ 9, \$ 10, \$ 11, \$ 12, \$ 13, \$ 14$, dan $\$ 15$. Tingkat suku bunga yang digunakan dalam penelitian ini adalah suku bunga yang dikeluarkan oleh pihak yang berwenang yaitu Bank Indonesia pada bulan Juli 2016 yaitu sebesar $6.5 \%$.

\section{Menentukan Nilai Return (Tingkat Pengembalian)}

Menentukan nilai $R_{t}$ (Return saham pada waktu $t$ ) dengan persamaan berikut:

$$
R_{t}=\left(\frac{S_{t}-S_{t-1}}{S_{t-1}}\right)
$$

Data historis akan disubstitusi ke persamaan (4) untuk menghitung $R_{t}$. Untuk nilai $R_{t}$ dengan $1 \leq t \leq 253$.

\section{Menentukan Nilai Statistika Deskriptif}

Menghitung nilai statistika deskriptif dicari dengan memanfaatkan data dari nilai return. Dalam proses ini nilai mean $(E)$, varian $(V)$, skewness $(S)$, kurtosis $(K)$ dan standar deviasi dihitung dengan bantuan MS excel. Sehingga didapat hasil seperti pada Tabel 1.
Tabel 1. Nilai Statistik Deskriptif

\begin{tabular}{|l|l|}
\hline & Nilai \\
\hline Mean $(E)$ & 0,001154 \\
\hline Varian $(V)$ & 0,00359 \\
\hline Skewness $(S)$ & 0,519988 \\
\hline Kurtosis $(K)$ & 2,176908 \\
\hline Standar Deviasi $(\sigma)$ & 0,059915 \\
\hline
\end{tabular}

Dari Tabel 1 dapat dilihat bahwa data tersebut memiliki bentuk yang tidak simetris, yaitu mencong ke kanan karena memiliki nilai skewness positif, dan dilihat dari nilai kurtosis yang lebih kecil dari 3 maka disebut sebagai platikurtik (kurva datar).

\section{Menentukan Nilai Parameter Awal $u, d$, dan $p$}

Parameter $u, d$, dan $p$ adalah parameter awal yang akan dipakai dalam metode binomial. Dengan menggunakan nilai statistika deskriptif yang telah didapat, maka selanjutnya akan dapat dihitung nilai-nilai dari parameter awal. Sebelumnya telah dihitung nilai statistika deskriptif dimana nilai dari standar deviasi akan digunakan sebagai nilai dari $\sigma$. Berikut dipaparkan variabel-variabel yang digunakan untuk menentukan nilai parameter awal sebagai berikut:

Tabel 2. Nilai Variabel-variabel untuk Menentukan Parameter Awal

\begin{tabular}{|c|l|}
\hline Variabel & Nilai \\
\hline$\sigma$ & 0,059915 \\
\hline$T$ & 0,25 \\
\hline$M$ & 5 \\
\hline $\mathrm{r}$ & 0,065 \\
\hline$\Delta t=\frac{T}{M}$ & $0 ., 05$ \\
\hline
\end{tabular}

Langkah pertama adalah menghitung nilai parameter $u$ sebagai berikut,

$$
\begin{aligned}
u & =e^{\left(r-\frac{1}{2} \sigma^{2}\right) \Delta t+\sigma \sqrt{\Delta t}} \\
& =e^{\left(0,065-\frac{1}{2}(0,059915)^{2}\right) 0,05+0,05915 \sqrt{0,05}} \\
& =e^{\left(0,065-\frac{1}{2}(0,0036) 0,05+0,05915(0,224)\right.} \\
& =e^{(0,065-0,0018) 0,05+0,0134} \\
& =1,0167 .
\end{aligned}
$$


kemudian nilai parameter d didapat dari,

$$
\begin{aligned}
d & =\frac{1}{u}=\frac{1}{1,0167} \\
& =0,9836 .
\end{aligned}
$$

Langkah kedua, karena nilai parameter $u$ dan $d$ telah ditemukan maka probabilitas gerakan naik dan turun masing-masing adalah

$$
\begin{aligned}
& \begin{aligned}
p & =\frac{e^{r \Delta t}-d}{u-d} \\
& =\frac{e^{0,065(0,05)}-0,9836}{1,0167-0,9836} \\
& =0,5936
\end{aligned} \\
& \text { dan } \\
& 1-p=1-0,5936=0,4064 .
\end{aligned}
$$

\section{Simulasi Harga Kontrak Opsi Tipe Eropa Menggunakan Pohon Binomial}

Simulasi ini diproses menggunakan metode pohon binomial dengan tujuan menafsir harga kontrak opsi tipe Eropa pada komoditas emas.

Untuk melakukan simulasi setelah mendapatkan parameter yang diperlukan, yang selanjutnya dilakukan adalah membentuk pohon binomial seperti pada Gambar 1.

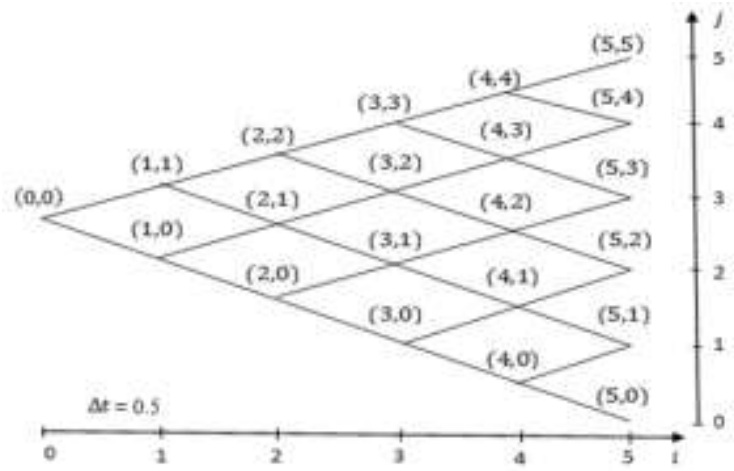

Gambar 1. Pohon Binomial untuk 5 Periode

Setiap node pada Gambar 1 dihitung menggunakan rumus metode pohon binomial dalam perhitungan kontrak opsi tipe Eropa pada persamaan (2) dan persamaan (3). Harga kontrak opsi tipe Eropa pada komoditas emas dapat diperoleh dengan mendiskonto nilai dari simpul terakhir pada pohon binomial.

Dari data historis telah diperoleh harga awal $\left(S_{0}\right)=\$ 12,87$, sedangkan dari semua harga pelaksanaan (strike price) yang disepakati antara penjual dan pembeli opsi diambil salah satu untuk melakukan perhitungan manual yaitu sebesar $K=\$ 13$, kemudian telah didapat nilai parameter $u=1,0167, \quad d=0,9836, p=$ 0,5936 dan $(1-p)=0,4064$. Harga kontrak opsi jual tipe Eropa pada simpul yang terakhir dihitung menggunakan persamaan:

$f_{i, j}=\max \left(K-S_{0} u^{j} d^{N-j}, 0\right)$.

Karena begitu banyak perhitungan untuk setiap simpul yang terdapat pada pohon binomial, penulis hanya memaparkan beberapa perhitungan sebagai contoh yaitu pada simpul $f_{5,0}, f_{3,1}$, dan $f_{0,0}$ sebagai berikut:

$f_{i, j}=\max \left(K-S_{0} u^{j} d^{N-j}, 0\right)$

$f_{5,0}$

$$
\begin{aligned}
& =\max \left(13-\left(12,87^{*} 1,0167^{0 *} 0,9836^{5-0}\right), 0\right) \\
& =\max \left(13-\left(12,87^{*} 1^{*} 0,9836^{5}\right), 0\right) \\
& =\max \left(13-\left(12,87^{*} 0,9206\right), 0\right) \\
& =\max (13-11,8481,0) \\
& =\max (1,1519,0) \\
& =1,1519
\end{aligned}
$$

Selanjutnya untuk semua simpul selain simpul terakhir dihitung dengan menggunakan persamaan:

$$
f_{i, j}=e^{-r \Delta t}\left[p f_{i+1, j+1}+(1-p) f_{i+1, j}\right]
$$

Berikut beberapa perhitungan untuk simpulsimpul selain simpul terakhir pada pohon yaitu,

$$
\begin{aligned}
f_{i, j}= & e^{-r \Delta t}\left[p f_{i+1, j+1}+(1-p) f_{i+1, j}\right] \\
f_{3,1}= & e^{-0,065^{*} 0,05}\left[0,5936 f_{3+1,1+1}\right. \\
& \left.+0,4064 f_{3+1,1}\right] \\
= & e^{-0,00325}\left[0,5936 f_{4,2}+0,4064 f_{4,1}\right] \\
= & 0,9967\left[\left(0,5936^{*} 0,1376\right)\right. \\
= & \left.\quad+\left(0,4064^{*} 0,5059\right)\right] \\
= & 0,9967[0,0817+0,2056] \\
= & 0,2863
\end{aligned}
$$

Demikian pula untuk simpul $f_{0,0}$ didapat hasil:

$$
\begin{aligned}
f_{i, j}= & e^{-r \Delta t}\left[p f_{i+1, j+1}+(1-p) f_{i+1, j}\right] \\
f_{0,0}= & e^{-0,065^{*} 0,05}\left[0,5936 f_{0+1,0+1}\right. \\
& \left.\quad+0,4064 f_{0+1,0}\right] \\
= & e^{-0.00325}\left[0,5936 f_{1,1}+0,4064 f_{1,0}\right] \\
= & 0,9967\left[\left(0,5936^{*} 0,0735\right)\right. \\
= & \left.\quad+\left(0,4064^{*} 0,2663\right)\right] \\
= & 0,9967[0,0436+0,01082] \\
= & 0,1513
\end{aligned}
$$


Sehingga pohon yang terbentuk sebagai berikut:

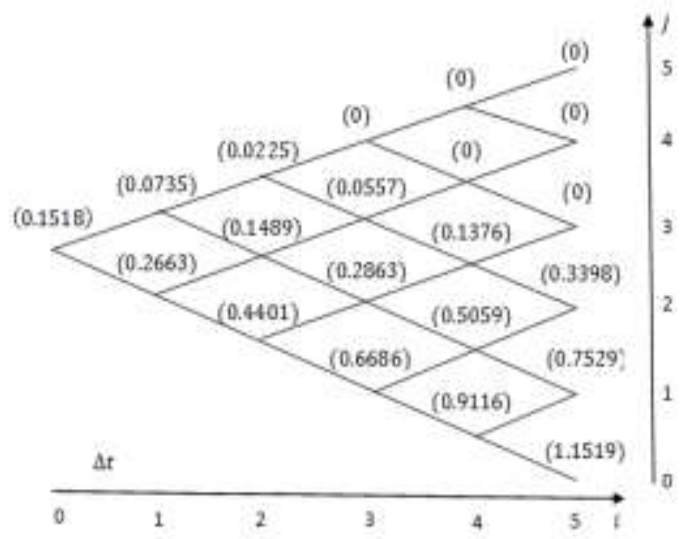

Gambar 2. Bentuk Hasil Pohon Binomial

Rata-rata dari simpul akhir sebesar 0,3741 selanjutnya didiskonto menggunakan simulasi dengan harga pelaksana \$13 diperoleh,

$$
\begin{gathered}
e^{-r \Delta t *} r a t a-r a t a=e^{-0,065^{*} 0,05 *} 0,3741 \\
=e^{-0,00325^{*} 0,3741} \\
=0,9967^{*} 0,3741 \\
=0,3729
\end{gathered}
$$

Sehingga harga kontrak opsi jual komoditas emas untuk harga pelaksana $(K)$ sebesar $\$ 13$ adalah $\$ 0,3729$. Perhitungan untuk 7 harga pelaksana yang berbeda dilakukan menggunakan bantuan program Matlab R2013a.

\section{Hasil Estimasi Harga Kontrak Opsi Tipe Eropa Menggunakan Pohon Binomial}

Tabel 3. Harga Simulasi Kontrak Opsi Tipe Eropa Mengunakan Metode Pohon Binomial

\begin{tabular}{|c|c|c|c|}
\hline $\begin{array}{c}\text { Harga (\$) } \\
\text { pelaksana }\end{array}$ & $\begin{array}{c}\text { Harga (\$) } \\
\text { awal }\end{array}$ & $\begin{array}{c}\text { Harga (\$) kontrak opsi } \\
\text { Pohon Binomial } \\
\text { (Binomial Tree) }\end{array}$ \\
\cline { 3 - 4 } & & call & put \\
\hline 9 & 12,87 & 4,0151 & 0 \\
\hline 10 & 12,87 & 3,0312 & 0 \\
\hline 11 & 12,87 & 2,0473 & 0 \\
\hline 12 & 12,87 & 1,0634 & 0 \\
\hline 13 & 12,87 & 0,1915 & 0,3768 \\
\hline 14 & 12,87 & 0 & 1,3374 \\
\hline 15 & 12,87 & 0 & 2,3374 \\
\hline
\end{tabular}

Pada Tabel 3 dapat dilihat harga kontrak opsi beli (call) dan opsi jual (put) tipe Eropa dengan harga pelaksana yang berbeda. Pada tabel harga kontrak opsi call menunjukkan bahwa semakin besar harga pelaksana maka semakin murah harga kontrak opsinya, hal itu dikarenakan harga komoditas $(S)$ lebih besar dari harga pelaksana $(K)$. Sedangkan untuk harga kontrak opsi put sebaliknya.

\section{Simulasi Harga Kontrak Opsi Tipe Eropa Menggunakan Black-Scholes}

Harga opsi jual tipe Eropa menggunakan metode Black-Scholes ditentukan dengan rumus sebagai berikut, dengan,

$$
P_{B S}=K e^{-r t} N\left(-d_{2}\right)-S_{0} N\left(-d_{1}\right)
$$

$$
\begin{aligned}
d_{1} & =\frac{\ln \left(\frac{S_{0}}{K}\right)+\left(r+\frac{\sigma_{T}^{2}}{2}\right) T}{\sigma_{T} \sqrt{T}} \\
d_{2} & =\frac{\ln \left(\frac{S_{0}}{K}\right)+\left(r-\frac{\sigma_{T}^{2}}{2}\right) T}{\sigma_{T} \sqrt{T}} \\
& =d_{1}-\sigma_{T} \sqrt{T}
\end{aligned}
$$

Dengan $S_{0}$ (harga saham awal), $T$ (waktu jatuh tempo), $K$ (Strike price), $r$ (suku bunga bebas risiko, $\sigma$ (volatilitas harga saham) dan $N\left(-d_{1}\right)$ merupakan fungsi densitas kumulatif distribusi normal dari $d_{1}$, sedangkan $N\left(-d_{2}\right)$ merupakan fungsi densitas kumulatif distribusi normal dari $d_{2}$.

Untuk menghitung harga kontrak opsi jual tipe Eropa dengan harga awal $\left(S_{0}\right)$ adalah $\$ 12,87$ dengan harga pelaksana $(K)$ yang digunakan adalah $\$ 13$, tingkat suku bunga bebas resiko $(r)$ sebesar $6,5 \%$ dan volatilitas $(\sigma)$ yang ditentukan dari nilai standar deviasi pada statistika deskriptif adalah 0,059915, langkah awal yang dilakukan adalah menghitung komponen $d_{1}$ dan $d_{2}$ sebagai berikut,

$$
\begin{aligned}
d_{1} & =\frac{\ln \left(\frac{S_{0}}{K}\right)+\left(r+\frac{\sigma_{T}{ }^{2}}{2}\right) T}{\sigma_{T} \sqrt{T}} \\
& =\frac{\ln \left(\frac{12,87}{13}\right)+\left(0,065+\frac{0,059915^{2}}{2}\right) 0,25}{0,059915 \sqrt{0,25}} \\
& =0,221927399 \\
d_{2} & =d_{1}-\sigma_{T} \sqrt{T} \\
& =0,221927399-0,059915 \sqrt{0,25} \\
& =0,191969899
\end{aligned}
$$


Selanjutnya akan dicari nilai dari $N\left(-d_{1}\right)$ dan $N\left(-d_{2}\right)$ dengan bantuan software Microsoft Excel masing-masing dengan nilai sebagai berikut

$$
\begin{aligned}
& N\left(-d_{1}\right)=0,412185 \\
& N\left(-d_{2}\right)=0,423883
\end{aligned}
$$

Sehingga harga kontrak opsi jual tipe Eropa pada komoditas adalah sebagai berikut

$$
\begin{aligned}
P_{B S} & =K e^{-r t} N\left(-d_{2}\right)-S_{0} N\left(-d_{1}\right) \\
& =13\left(e^{-0.065(0.25)}\right)(0,412185) \\
& \quad-12,87(0,423883) \\
& =0,116831846 .
\end{aligned}
$$

\section{Hasil Estimasi Harga Kontrak Opsi tipe Eropa pada Komoditas Emas Tipe Eropa Menggunakan Metode Black-Scholes}

Metode Black-Scholes mengasumsikan bahwa tidak adanya pembayaran dividen, dan biaya transaksi sehingga pada Tabel 4 harga kontrak opsi call menunjukkan bahwa semakin besar harga pelaksana maka semakin murah harga kontrak opsinya, hal itu dikarenakan harga komoditas $(S)$ lebih besar harga pelaksana $(K)$. Sedangkan untuk harga kontrak opsi put sebaliknya.

Tabel 4. Harga simulasi kontrak opsi call tipe Eropa mengunakan metode BlackScholes

\begin{tabular}{|c|c|c|c|}
\hline $\begin{array}{c}\text { Harga (\$) } \\
\text { pelaksana }\end{array}$ & $\begin{array}{c}\text { Harga (\$) } \\
\text { awal }\end{array}$ & \multicolumn{2}{|c|}{$\begin{array}{c}\text { Harga (\$) kontrak opsi } \\
\text { Black-Scholes }\end{array}$} \\
\cline { 3 - 4 } & & call & put \\
\hline 9 & 12,87 & 4,0151 & 0 \\
\hline 10 & 12,87 & 3,0312 & 0 \\
\hline 11 & 12,87 & 2,0335 & 0 \\
\hline 12 & 12,87 & 1,0636 & 0 \\
\hline 13 & 12,87 & 0,1964 & 0,1168 \\
\hline 14 & 12,87 & 0,0016 & 0,9059 \\
\hline 15 & 12,87 & 0 & 1,8882 \\
\hline
\end{tabular}

\section{Interpretasi Hasil Estimasi Harga Kontrak Opsi Tipe Eropa Menggunakan Binomial Tree dan Black scholes}

Dari hasil Tabel 5 dapat dilihat bahwa harga kontrak opsi beli (call) tipe Eropa pada metode pohon binomial cenderung lebih murah $d$ bandingkan dengan harga kontrak opsi beli (call) tipe Eropa dengan menggunakan metode
Black-Scholes, sebaliknya pada opsi jual (put) harga kontrak opsi pada metode pohon binomial cenderung lebih mahal.

Tabel 5. Perbandingan Harga kontrak Opsi Tipe Eropa Menggunakan Pohon Binomial (Binomial Tree) dan Black-Scholes

\begin{tabular}{|c|c|c|c|c|c|}
\hline $\begin{array}{c}\text { Harga } \\
\begin{array}{c}\$ \\
\text { pelak- } \\
\text { sana }\end{array}\end{array}$ & $\begin{array}{c}\text { Harga } \\
(\$) \\
\text { awal }\end{array}$ & \multicolumn{2}{|c|}{$\begin{array}{c}\text { Harga (\$) kontrak } \\
\text { opsi Pohon } \\
\text { Binomial }\end{array}$} & \multicolumn{2}{|c|}{$\begin{array}{c}\text { Harga (\$) kontrak } \\
\text { opsi Black- } \\
\text { Scholes }\end{array}$} \\
\cline { 3 - 6 } & call & put & call & put \\
\hline 9 & 12,87 & 4,0151 & 0 & 4,0151 & 0 \\
\hline 10 & 12,87 & 3,0312 & 0 & 3,0312 & 0 \\
\hline 11 & 12,87 & 2,0473 & 0 & 2,0335 & 0 \\
\hline 12 & 12,87 & 1,0634 & 0 & 1,0636 & 0 \\
\hline 13 & 12,87 & 0,1915 & 0,3768 & 0,1964 & 0,1168 \\
\hline 14 & 12,87 & 0 & 1,3374 & 0,0016 & 0,9059 \\
\hline 15 & 12,87 & 0 & 2,3374 & 0 & 1,8882 \\
\hline
\end{tabular}

\section{KESIMPULAN DAN SARAN}

\section{Kesimpulan}

Dalam menentukan harga kontrak opsi beli (call) dan opsi jual (put) tipe Eropa pada harga saham perusahaan Freeport-McMoRan Inc. (FCX) menggunakan metode pohon binomial (Binomial Trees) terdapat beberapa faktor yang memengaruhi yaitu $S_{0}$ (harga komoditas awal), $T$ (waktu jatuh tempo), $K$ (Strike price), $r$ (suku bunga bebas risiko) dan volatilitas.

Harga kontrak opsi beli (call) tipe Eropa pada metode pohon binomial cenderung lebih murah dibandingkan dengan harga kontrak opsi beli (call) tipe Eropa dengan menggunakan metode Black-Scholes, sebaliknya pada opsi jual (put) harga kontrak opsi pada metode pohon binomial cenderung lebih mahal.

\section{Saran}

Pengembangan penelitian selanjutnya, diharapkan dalam penentuan harga kontrak opsi tipe Eropa disertakannya dividend dan suku bunga yang tidak konstan. Perhitungan harga kontrak opsi dapat dilakukan dengan menggunakan Metode Trinomial. 


\section{DAFTAR PUSTAKA}

Mastro, M. (2013). Financial Derivative and Energi Market Valuation. Canada: John Wiley \& Sons, Inc., Hoboken, New Jersey.

Tandelilin, E. (2001). Analisis Investasi dan Manajemen Portofolio (1nd ed.).

Yogyakarta: BPFE. 